\section{Occurrence of Conjugated Dienoic} Fatty Acids in the Cellular Lipids of Pediococcus homari

\section{Kinji UCHIDA}

\section{Central Research Laboratories, Kikkoman Shoyu Co., Ltd., Noda, Chiba-ken 278}

Received November 5, 1974

It has been generally believed that bacteria are unable to synthesize polyunsaturated fatty acids, in contrast to all other life forms. ${ }^{1)}$ Only one exception hitherto unequivocally known is Bacillus licheniformis ATCC 9295') which was shown to form a small amount of 5,10-hexadecadienoic acid through repeated oxidative desaturations of palmitic acid, under the limited conditions of cultural temperature. The present communication describes the occurrence of several conjugated di-unsaturated fatty acids in the cellular lipids of $P$. homari, a moderately halo-tolerant lactic acid coccus.

Previously, the author found an appreciable amount of unknown fatty acids with unusual GLC properties in the cellular fatty acids of
$P$. homari. ${ }^{3)}$ A preliminary examination of these unknown acids and their hydrogenated products on GLC columns of different polarities suggested that they were relatively highly unsaturated fatty acids of $\mathrm{C}_{16}, \mathrm{C}_{18}$, and $\mathrm{C}_{20 .}{ }^{43}$

$P$ homari NISL 7136 was cultivated in the medium $\mathrm{A}$ as previously reported. ${ }^{4}$ Conditions for harvest of the cells and for extraction, methylation and GLC analysis of the cellular fatty acids were almost the same as described before. ${ }^{4,5)}$ The methyl esters were then separated into saturated, mono-unsaturated and slow migrating unknown fatty acid fractions by means of $\mathrm{AgNO}_{3}$-impregnated silicagel thin-layer chromatography. ${ }^{6}{ }^{\prime}$ When the unknown fraction was analyzed by GLC, four major peaks were obtained along with several minor components. Hydrogenation of the unknown fraction under 1 atm with a paladium catalyst resulted in the production of palmitic and stearic acids, suggesting that the unknown acids were consisted mainly of $\mathrm{C}_{10^{-}}$, and $\mathrm{C}_{18^{-}}$-straight-chain unsaturated acids. An extensive examination of GLC behavior of the unknown acids with DEGS (diethyleneglycol succinate polyester, $20 \%$ on Chromosorb W DMCS, $3 \mathrm{~mm} \times 2 \mathrm{~m}$ ), XE-60

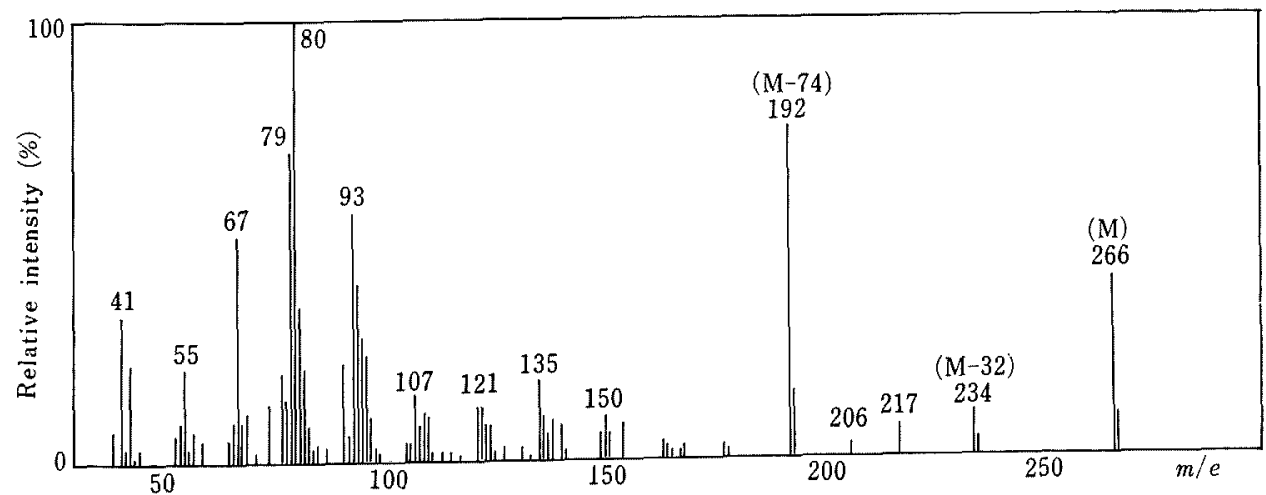

FIG. 1. Mass Spectrum of the Methyl cis,cis-Conjugated Hexadecadienoate Isolated from $P$. homari. Mass spectrum was obtained from a Hitachi 063-RMU.7M combined GLC-mass spectrometer working with an ionizing electron energy of $70 \mathrm{eV}$, an accelerating voltage of $3.2 \mathrm{kV}$, and an electron current of $100 \mu \mathrm{A}$. The separator and the connection part were maintained at $250^{\circ} \mathrm{C}$. The GLC column was a $3 \mathrm{~mm} \times 2 \mathrm{~m}$ stainless steel column packed with $10 \%$ FFAP/Diasolid L, $60 \sim 80 \mathrm{mesh}$, and operated at $200^{\circ} \mathrm{C}$ with $\mathrm{He}$ as the carrier gas.

Abbreviation: GLC, gas liquid chromatography. 


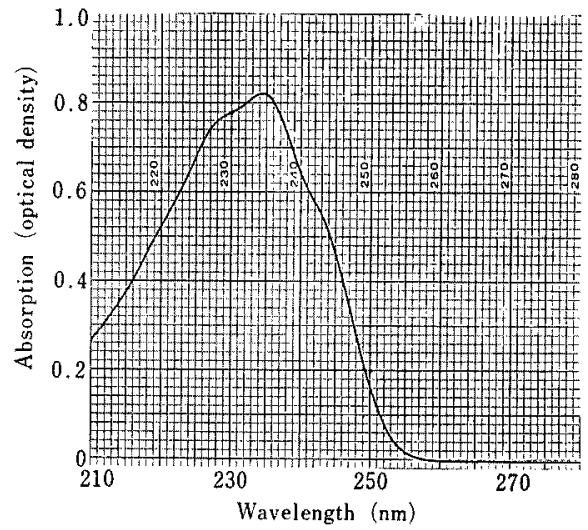

Frg. 2. Ultraviolet Absorption Spectrum of the Methyl cis,cis-Conjugated Hexadecadienoate Isolated from $P$. homari.

About $8 \mu \mathrm{g} / \mathrm{ml}$ solution of the methyl ester in spectral grade $n$-hexane (Tokyo Kasei Kogyo Co., Ltd.) was determined for its UV absorption with a Hitachi 323 Recording Spectrophotometer.

$(15 \%, 3 \mathrm{~mm} \times 1 \mathrm{~m})$, and SE-52 $(10 \%, 3 \mathrm{~mm} \times$ $1 \mathrm{~m})$ columns revealed that the major acids could be grouped into two homologous series, $\mathrm{X}$ or $\mathrm{Y}$, mutually distinguishable but similar in structure. Thus, the four major unknown acids having equivalent chain lengths of $18.14,18.44,20.14$, and 20.50 on the DEGS column were temporarily designated as $16-X, 16-Y, 18-X$, and $18-Y$, respectively. The number denotes the length of the carbon chain, and $\mathrm{X}$ or $\mathrm{Y}$ indicates the homologous series of the acids.

Gas chromatography-mass spectrometry showed that the four unknown acids were all di-unsaturated acids ${ }^{7}$ (Fig. 1). Unexpectedly, the mass spectra of X-, and Y-acids of the same chain lengths were almost consistent with each other. This suggested that the $\mathrm{X}$-, and $\mathrm{Y}$-series acids differed only in the configuration of the unsaturated bonds.

The unknown acids were separated individually by preparative $\mathrm{GLC}^{6)}$ using a $3 \mathrm{~mm} \times$ $2 \mathrm{~m}$ column packed with $15 \%$ SE-52 coated Chromosorb W DMCS 60 80 mesh. Four isolates of $80 \sim 85 \%$ purities, $16-\mathrm{X}, 16-\mathrm{Y}$, $18-X$, and $18-Y$, were obtained and were determined for their ultraviolet and infrared spectra. ${ }^{6}$ All these unknown acids were shown to have strong ultraviolet absorption $\left(\varepsilon=\right.$ about $\left.2.8 \times 10^{4}\right)$, characteristic to conjugated dienes. The absorption maxima of $16-X$ and $18-X$ were at $233 \mathrm{~nm}$, and those of $16-\mathrm{Y}$ and $18-\mathrm{Y}$ were at $235 \mathrm{~nm}$; this finding suggested that the $\mathrm{X}$-, and $\mathrm{Y}$-series acids had cis,trans-, and cis, cis-configurations, ${ }^{83}$ respectively. An infrared spectrum of 16-X showed two absorption bands at 948 and $982 \mathrm{~cm}^{-1}$; these facts were indicative of a cis,trans-conjugated dienoic structure. ${ }^{81}$ Spectra of both 16-Y and 18-Y, however, did not show any diagnostic absorption over the wave range of $900 \sim 1000 \mathrm{~cm}^{-1}$, indicating that the conjugated dienes in the $Y$-series acids were $c i s$, cis-configuration. Infrared spectrometry of $18-\mathrm{X}$ was not performed because of the meager amount of the isolate.

On the bases of these experimental data, the $16-X, 16-Y, 18-X$, and $18-Y$ acids were tentatively identified as cis,trans-conjugated hexadecadienoic, cis,cis-conjugated hexadecadienoic, cis,trans-conjugated octadecadienoic, and cis,cis-conjugated octadecadienoic acids, respectively. The retention data of $\mathrm{C}_{18}$-conjugated dienoic acids in GLC are almost consistent with those published before." Determination of the positions of conjugated double bonds in these unusual acids is now in progress. It was assumed, however, from the mass spectral data, that the double bonds were located relatively closely to the carboxyl groups in the $\mathrm{C}_{16}$-acids. ${ }^{7}$

To our best knowledge, this is the first report for isolation of conjugated dienoic acids from bacteria. ${ }^{10)}$ It should be noted that these unusual acids comprised up to $80 \%$ of the total fatty acids in this bacterium, under certain cultural conditions. A new mechansim for synthesizing unsaturated fatty acid must be involved in the fatty acid biosynthesis by P. homari.

Acknowledgements. The author express his thanks to Prof. K.Arima of Tokyo University for the guidance in this work. Assistance of Mr. M. Sasaki and N. Nunomura in mass spectrometry is gratefully acknowledged, 


\section{REFERENCES}

1) "Lipids and Biomembranes of Eukaryotic Microorganisms," ed. by J. A. Erwin, Academic Press, New York, 1973, p. 70.

2) A. J. Fulco, J. Biol. Chem, 245, 2985 (1970).

3) K. Uchida and K. Mogi, Agr. Biol. Chem., 35, 136 (1971).

4) K. Uchida and K. Mogi, J. Gen. Appl. Microbiol., 18, 109 (1972).
5) K. Uchida and K. Mogi, J. Gen. Appl. Microbiol., 19, 233 (1973).

6) K. Uchida, Biochim. Biophys. Acta, 348, 86 (1974).

7) W. W. Christie and R. T. Holman, Chem. Phys. Lipids, 1, 407 (1967).

8) C. Y. Hopkins and M.J. Chisholm, J. Am. Oil Chem. Soc, 45, 176 (1968).

9) F. D. Gunstone and M. Lie Ken Jie, Chem. Phys. Lipids, 4, 131 (1970).

10) K. Uchida, Hakkô Kyôkaishi, 32, 471 (1974). 